\title{
Pharmaceutical Biochemistry at the ETH Zürich
}

\author{
Leonardo Scapozza*
}

\begin{abstract}
Pharmaceutical biochemistry at the ETH Zürich is devoted to research on ligand-macromolecule interactions, combining experiments with computational data as closely as possible because we believe that there is no rational disease treatment without molecular understanding of events. For this purpose biochemical/biophysical studies of target proteins in complex with their ligands are an essential part of the research. Complementary and integrated to it, a second field of research is dedicated to computational methods that play an important role in drug discovery and development. These methods are strongly interconnected with the experiments and are used to generate new hypotheses to be tested experimentally. This approach has been made feasible by the progress of molecular biology and computer technology and is now extensively used in all major pharmaceutical industries and thus has to be taught to students. Because of the interdisciplinarity of the research a multidisciplinary environment has been established. The scientific effort of the group is focused on cancer and antiviral research. Key targets of the research are kinases, namely thymidine kinases and tyrosine kinases of oncogenic fusion proteins. In parallel and in view of the increasing amount of experimental data generated by the different -omics initiatives the group has started the development of appropriate software tools for data mining.
\end{abstract}

Keywords: Drug design · Kinases · Ligand-macromolecule interaction · Protein engineering · Stem cells

\section{Pharmaceutical Biochemistry Within the Context of Pharmaceuti- cal Research}

The playground of pharmaceutical research is the human being and its complexity. The aim is to develop agents (small organic molecules, antibodies, therapeutic proteins) that would restore normal physiological conditions as closely as possible. The aim of research in pharma-

\footnotetext{
*Correspondence: Prof. Dr. L. Scapozza Departement für Chemie und Angewandte Biowissenschaften

Wolfgang-Pauli Str. 10

$\mathrm{CH}-8093$ Zürich

www.pharma.ethz.ch/pb

From 1.10.2004

Laboratory of Pharmaceutical Biochemistry

Institute of Medicinal Chemistry

School of Pharmacy

Geneva University

30 Quai Ansermet

$\mathrm{CH}-1211$ Geneva 4

Tel.: +4122379 3363

Fax: +41223793360

E-Mail: leonardo.scapozza@pharm.unige.ch
}

ceutical biochemistry is to foster the development of these agents by increasing the knowledge on ligand-macromolecule interaction at the molecular level by using an interdisciplinary approach combining biochemical/biophysical studies (mutagenesis, biochemical evaluation of the target protein and their ligands, crystallization, $\mathrm{X}$-ray structure determination, NMR, CD spectroscopy, microcalorimetry, surface plasmon resonance) of target proteins in complex with their ligands with computational approaches for drug design and data mining. This knowledge is an essential component for the development of targeted-based drugs that is favoured by the combination of methods, rather than any one experiment, as stated in a recent review by Arkin and Wells [1].

The following examples elucidate the approach taken in the pharmaceutical biochemistry group and how we hope to contribute to pharmaceutical research.

\section{Herpes Simplex Type I Thymidine Kinase: One Enzyme - Several Pharmaceutical Applications}

Thymidine kinases (TKs) were described for cellular life, long before it was shown that viruses could also encode them, but the viral thymidine kinase genes were the first to be sequenced. These enzymes have been extraordinarily useful to the researcher, serving first to help label DNA, then to get thymidine analogues incorporated into DNA for therapeutic and other purposes and more recently to move genes from one genome to another [2]. Thymidine kinases have been found in almost all organisms.

Thymidine kinase is the key enzyme in the pyrimidine salvage pathway catalyzing the phosphorylation of thymidine (dT) to thymidine monophosphate (dTMP) in the presence of $\mathrm{Mg}^{2+}$ and ATP [3] (Fig. 1). Regarding their sequence, molecular weight, and feedback sensitivity, TKs have been classified into two main groups, namely type I and II: the herpesviral thymidine kinases are of the type I, also called long TKs, while the poxviral and cellular thymidine kinases belong to type II, also called short TKs [2][4]. Herpes simplex type I thymidine kinase (HSV1 TK) is the representative enzyme of the type I thymidine kinases and displays a broad substrate acceptance phosphorylating both pyrimidine as well as purine analogs featuring modified sugar mimicry such as the antiviral drugs aciclovir and ganciclovir. Due to this broader substrate diversity in comparison to their cellular counterpart [5], they 


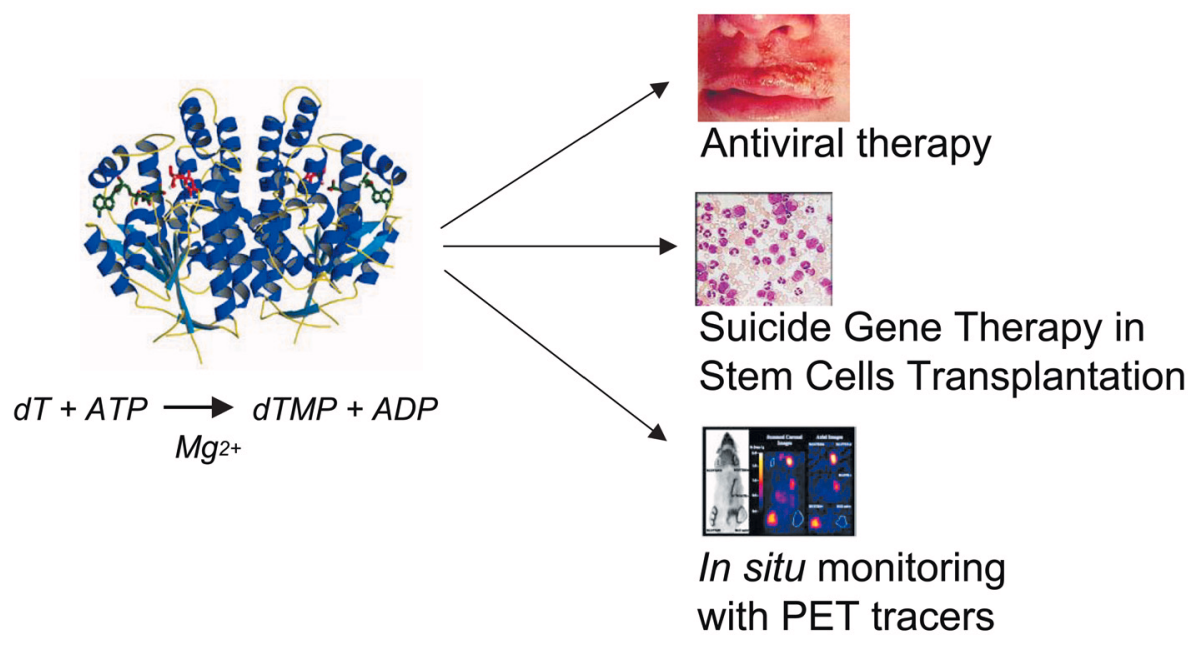

Fig. 1. Sketch of the medical-pharmaceutical fields in which HSV1 TK is involved. The structure of the enzyme is shown as a ribbon diagram, substrate (thymidine) and co-substrate (ATP) are depicted as stick models. The reaction converting thymidine (dT) in thymidine-monophosphate (dTMP) is indicated. PET stands for Positron Emission Tomography.

represent a selectivity filter for antiviral therapy [6] using aciclovir and its analogs. More recently it emerged as a suitable suicide gene to be used as safety tools for stem cell transplantation (SCT) within cancer therapy [7] and gene replacement therapy [8] (Fig. 1). Furthermore it reveals itself as a powerful reporter gene for in situ monitoring of protein expression [9] and localization of stem cells [10] (Fig. 1).

Hence our research focuses on the characterization of the molecular mechanism ruling the broad substrate specificity of HSV1 TK compared to human cytosolic TK in order to address the problem of resistance towards antiviral compounds and the clinical limitations such as immunogenicity and treatment incompatibility discovered during the clinical application of the suicide gene approach based on HSV1 TK/ganciclovir [11]. The achievement of this aim requires the following approaches and methods the group has specialized on:

- Exploration of the ligand binding process by combining thermodynamical measurements and structural information [12-14].

- Structure-based site directed mutagenesis to understand the peculiar broad substrate acceptance and engineer a new suicide gene that is tailor-made for novel drugs [15-19].

- Structure determination of the target protein in complex with newly developed antiviral compounds [18][20][21].

- Knowledge-based homology modeling of thymidine kinase and study of ligand binding by virtual docking [22][23].
- Exploration of the catalytic characteristics of HSV1 TK using quantum chemistry methodology within the density functional theory [24][25].

- Synthesis of new compounds to be used in antiviral therapy and/or precursors for the development of new positron emission tomography tracers [26-28].

- Target- and functional-based assay for assessing the efficiency in cell growth inhibition of the engineered TK in combination with several drugs [18][29-32].

\section{Inhibition of Tyrosine Kinase Domain of Oncogenic Fusion Protein: A Target-based Approach to Combat Cancer}

The generation of oncogenic fusion proteins (OFP) represents a clear example of a structurally abnormal protein being specifically expressed in neoplastic cells and causally linked to the process of malignant transformation. The hybrid genes coding for OFP derive from chromosomal translocations and fuse exons belonging to different genes [33]. They could be identified because the chromosomal alterations that generate them involve large exchanges of genetic material, and could therefore be detected using techniques like conventional cytogenetics.

OFP are causally related to the process of malignant transformation; in fact they are sometimes the only cytogenetic abnormality present, and the OFPs studied so far (BcrAbl, Pml-/Rara, Npm-Alk) can induce similar tumors in transgenic animals [34-36].
It is also important to note that these proteins are not only responsible for the transformation of cells, but are also involved in the maintenance of the transformed phenotype. The development of Gleevec as inhibitor of the kinase domain of Bcr-Abl clearly proved that when an OFP can be effectively targeted, the ensuing biological and pharmacological effects are considerable [37].

More than 30 different OFP have been identified and sequenced in the past 15 years, since the original cloning of the 9;22 translocation and the subsequent sequencing of the hybrid BCR-ABL gene [38], present in Chronic Myelogenous Leukemia (CML) and in a portion of Acute Lymphoblastic Leukemias (ALL). OFP are present in both leukemias and solid tumors, spanning from acute leukemia to thyroid papillary carcinoma and to Ewing's sarcoma.

Because of their causal relationship with the process of malignant transformation, OFP represent important targets for specific therapeutics attempts.

The research of the group focuses on three different OFP with protein tyrosine kinase (PTK) activity, Bcr-Abl, Npm-Alk, Ret (at least eight common somatic rearrangements result in fusions between the $\mathrm{N}$ terminus of various proteins and the PTK domain of Ret) [39]. The genes coding for these OFP cause Chronic Myeloid Leukemia or CML, part of Acute Lymphoblastic Leukemia or ALL (Bcr-Abl), the majority of Anaplastic large Cell Lymphomas (Npm-Alk), and multiple endocrine neoplasia 2A (MEN2A), MEN2B and familial medullary thyroid carcinoma (Ret) [39]. The total incidence of the cancers caused by these OFP is approximately $5 \times 10^{5}$ year. These cancers are highly aggressive, frequently incurable at present, and can develop in children and young adults, as well as at an older age. The PTK activity possessed by these OFP is fundamental for their transforming potency. Because of their biological (enzymatic) activity, the targeting of the catalytic domain of these proteins represents a rational strategy for developing new target-based cancer drugs.

The research of the group is aimed at addressing the following issues using the interdisciplinary approach described earlier:

- Conformational plasticity and structure-based drug design [40][41].

- The role of conformational changes of target protein in respect to resistance caused by mutations on the target [42][43] (Fig. 2).

- Finding new lead compounds as inhibitors to be developed into drug leads (Fig. 3) combining experiments and computational approaches as close as possible. 


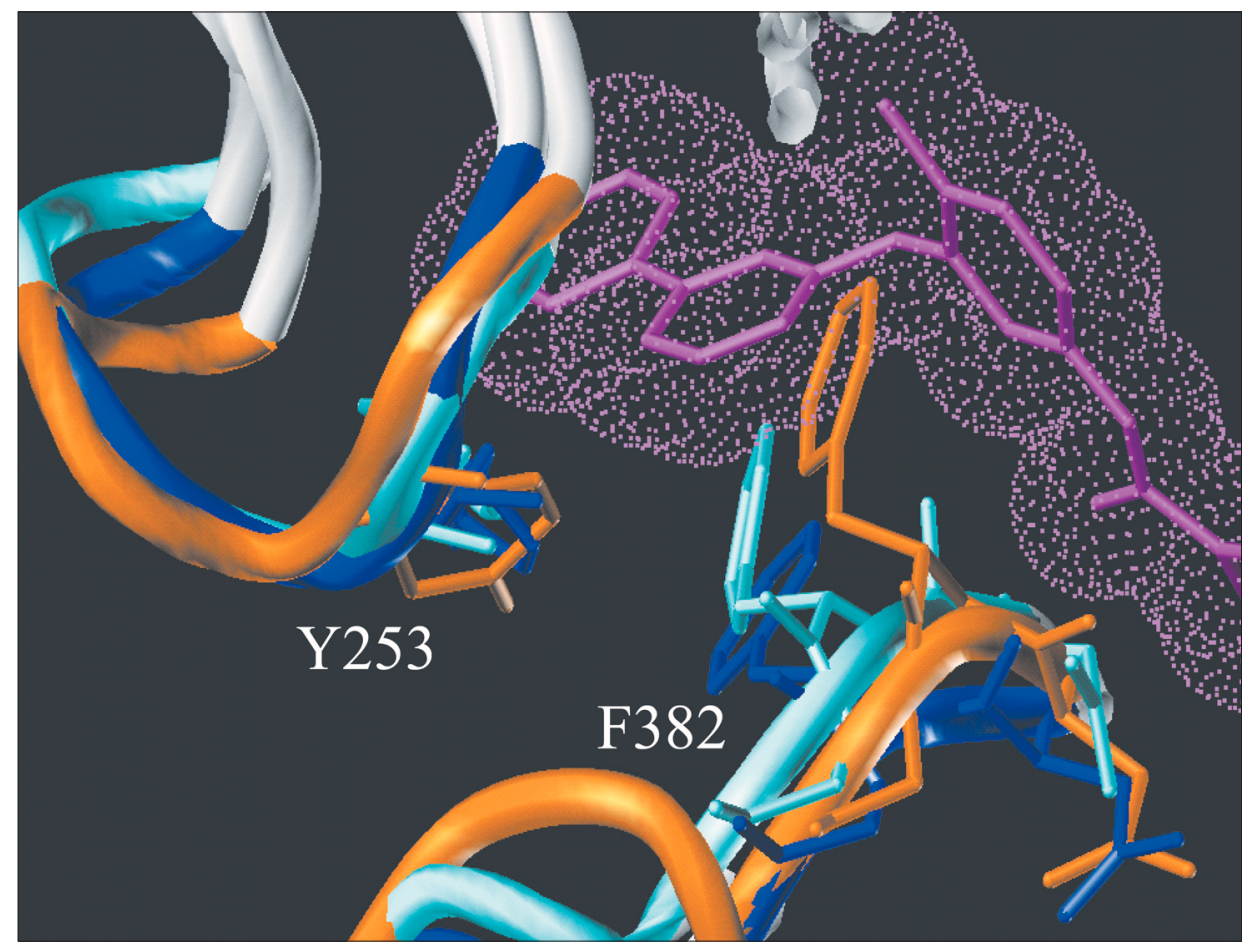

Fig. 2: Effect of a distant mutation H396P on the Bcr-Abl tyrosine kinase domain studied by molecular dynamic simulation. The X-ray structure of the wild-type tyrosine kinase domain of Bcr-Abl in complex with its specific inhibitor Gleevec [44] is shown as a blue tube. Gleevec is displayed as a magenta-capped stick model surrounded by its Van der Waals dot surface. The conformation of the wildtype enzyme and the mutant H396P after 1 ns molecular dynamic simulation are depicted in cyan and orange respectively. The side chain of tyrosine 253 and the highly conserved phenylalanine 382 of the DFG motif are indicated as capped stick model and labeled. In agreement with a decreased binding affinity of Gleevec for the mutated enzyme [45][46] the inhibitor does not fit properly within the binding site of the H396P mutant [43].

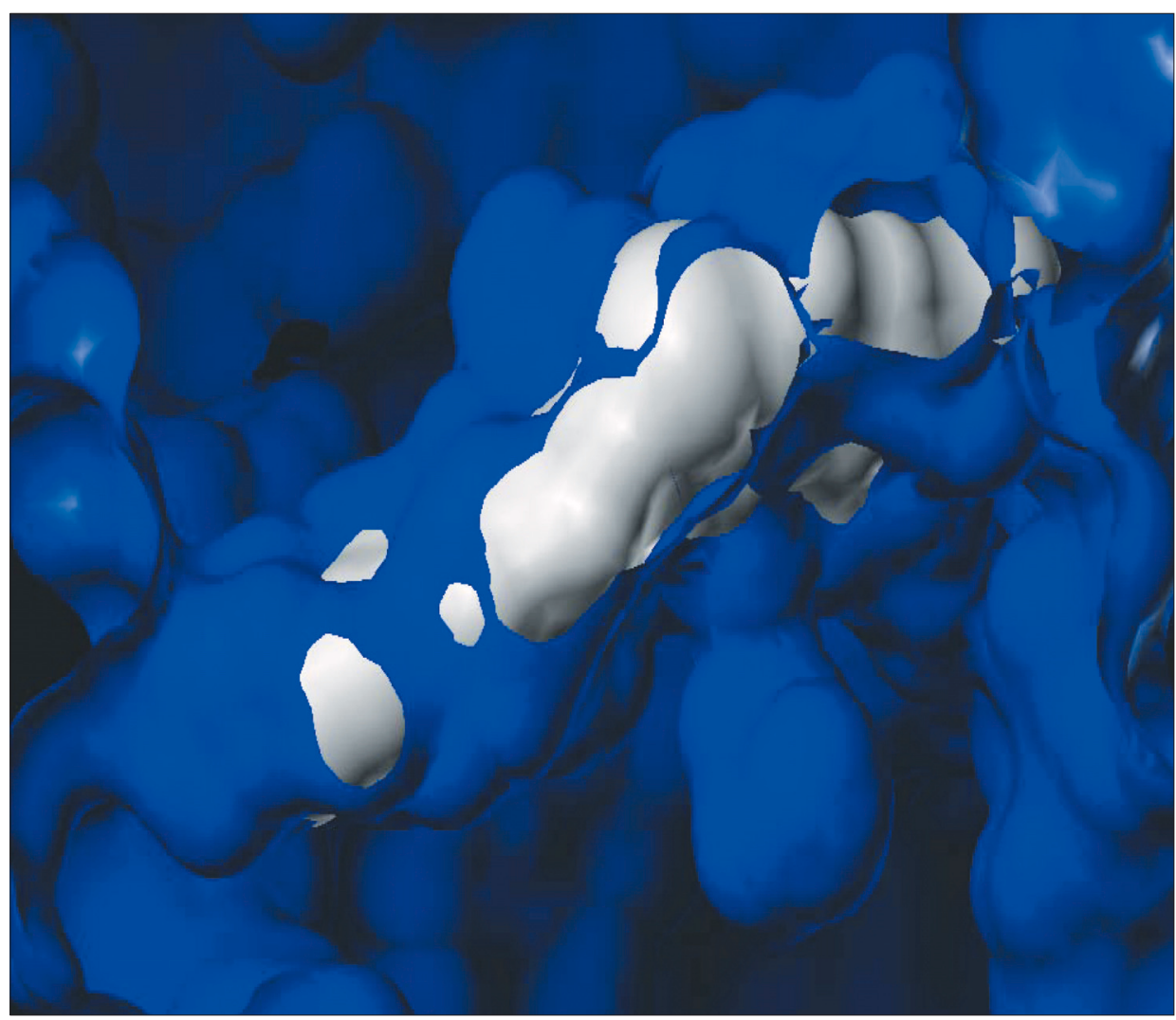

Fig. 3: Tyrosine kinase inhibitor binding to the Npm-Alk tyrosine kinase domain. The ligand is displayed as white surface while the surface of the enzyme indicating the binding site is shown in blue. The ligand has been found through virtual screening and shows an $\mathrm{IC}_{50}$ of $23 \mu \mathrm{M}$.
The success stories in drug development [1][37][47] show that working in an interdisciplinary way combining biochemical/biophysical studies, functional-based assays and chemistry with the most recent computational modeling techniques is a suitable approach to address issues that are interdisciplinary in nature such as discovery and development of drugs for the highly complex system, the human being [48][49]. By this approach, we hope to give new opportunities to the scientific community and companies by proposing new therapeutic concepts and supplying structural information and lead structures that could be further optimized.

Received: July 13, 2004

[1] M.R. Arkin, J.A. Wells, Nat. Rev. Drug. Discov. 2004, 3, 301-317.

[2] G.A. Gentry, Pharmacol. Ther. 1992, 54, 319-355.

[3] R. Okazaki, A. Kornberg, J. Biol. Chem. 1964, 239, 275-284.

[4] M.E. Black, D.E. Hruby, J. Biol. Chem. 1990, 265, 17584-17592.

[5] G.B. Elion, P.A. Furman, J.A. Fyfe, P. de Miranda, L. Beauchamp, H.J. Schaeffer, Proc. Natl. Acad. Sci. USA 1977, 74, 5716-5720.

[6] E. De Clercq, J. Clin. Virol. 2001, 22, 73-89.

[7] C. Bonini, G. Ferrari, S. Verzeletti, P. Servida, E. Zappone, L. Ruggieri, M. Ponzoni, S. Rossini, F. Mavilio, C. Traversari, C. Bordignon, Science 1997, 276, 1719-1724.

[8] D.B. Kohn, M. Sadelain, C. Dunbar, D. Bodine, H.P. Kiem, F. Candotti, J. Tisdale, I. Riviere, C.A. Blau, R.E. Richard, B. Sorrentino, J. Nolta, H. Malech, M. Brenner, K. Cornetta, J. Cavagnaro, K. High, J. Glorioso, Mol. Ther. 2003, 8, 180-187.

[9] S.S. Gambhir, Nat. Rev. Cancer 2002, 2, 683-693.

[10] G. Koehne, M. Doubrovin, E. Doubrovina, P. Zanzonico, H.F. Gallardo, A. Ivanova, J. Balatoni, J. Teruya-Feldstein, G. Heller, C. May, V. Ponomarev, S. Ruan, R. Finn, R.G. Blasberg, W. Bornmann, I. Riviere, M. Sadelain, R.J. O'Reilly, S.M. Larson, J.G. Tjuvajev, Nat. Biotechnol. 2003, 21, 405-413.

[11] S. Verzeletti, C. Bonini, S. Marktel, N. Nobili, F. Ciceri, C. Traversari, C. Bordignon, Hum. Gene Ther. 1998, 9, 2243-2251.

[12] R. Perozzo, I. Jelesarov, H.R. Bosshard, G. Folkers, L. Scapozza, J. Biol. Chem. 2000, 275, 16139-16145.

[13] T. Gerharz, S. Reinelt, S. Kaspar, L. Scapozza, M. Bott, Biochemistry 2003 , 42, 5917-5924.

[14] R. Perozzo, G. Folkers, L. Scapozza, $J$. Recept. Signal Transduct. Res. 2004, 24, $1-52$.

[15] S. Kussmann-Gerber, O. Kuonen, G. Folkers, B.D. Pilger, L. Scapozza, Eur. J. Biochem. 1998, 255, 472-481. 
[16] B.D. Pilger, R. Perozzo, F. Alber, C. Wurth, G. Folkers, L. Scapozza, J. Biol. Chem. 1999, 274, 31967-31973.

[17] A. Prota, J. Vogt, B. Pilger, R. Perozzo, C. Wurth, V.E. Marquez, P. Russ, G.E. Schulz, G. Folkers, L. Scapozza, Biochemistry 2000, 39, 9597-9603.

[18] P. Schelling, M.T. Claus, R. Johner, V.E. Marquez, G.E. Schulz, L. Scapozza, J. Biol. Chem. 2004, 25, 25.

[19] F.C. Christians, L. Scapozza, A. Crameri, G. Folkers, W.P. Stemmer, Nat. Biotechnol. 1999, 17, 259-264.

[20] J. Vogt, R. Perozzo, A. Pautsch, A. Prota, P. Schelling, B. Pilger, G. Folkers, L. Scapozza, G.E. Schulz, Proteins 2000, $41,545-553$

[21] C. Wurth, U. Kessler, J. Vogt, G.E. Schulz, G. Folkers, L. Scapozza, Protein Sci. 2001, 10, 63-73.

[22] P. Pospisil, T. Kuoni, L. Scapozza, G. Folkers, J. Recept. Signal. Transduct. Res. 2002, 22, 141-154.

[23] L. Spadola, E. Novellino, G. Folkers, L. Scapozza, Eur. J. Med. Chem. 2003, 38, 413-419.

[24] F. Alber, O. Kuonen, L. Scapozza, G. Folkers, P. Carloni, Proteins 1998, 31, 453-459.

[25] M. Sulpizi, P. Schelling, G. Folkers, P. Carloni, L. Scapozza, J. Biol. Chem. 2001, 276, 21692-21697.

[26] S. Prekupec, D. Svedruzic, T. Gazivoda, D. Mrvos-Sermek, A. Nagl, M. Grdisa, K. Pavelic, J. Balzarini, E. De Clercq, G. Folkers, L. Scapozza, M. Mintas, S. Raic-Malic, J. Med. Chem. 2003, 46, 5763-5772.

[27] S. Raic-Malic, A. Johayem, S.M. Ametamey, S. Batinac, E. De Clercq, G. Folkers, L. Scapozza, Nucleosides, $\mathrm{Nu}$ - cleotides \& Nucleic Acids 2004, 23, in press.

[28] P. Pospisil, B.D. Pilger, S. Marveggio, P. Schelling, C. Wurth, M. Pongracic, M. Mintas, S. Raic Malic, G. Folkers, L. Scapozza, Helv. Chim. Acta 2002, 85 , $3237-3250$

[29] S. Kussmann-Gerber, C. Wurth, L. Scapozza, B.D. Pilger, V. Pliska, G. Folkers, Nucleosides Nucleotides 1999, 18, 311-330.

[30] C. Wurth, R.M. Thomas, G. Folkers, L. Scapozza, J. Mol. Biol. 2001, 313, 657-670.

[31] P. Schelling, G. Folkers, L. Scapozza, Anal. Biochem. 2001, 295, 82-87.

[32] P. Russ, P. Schelling, L. Scapozza, G. Folkers, E.D. Clercq, V.E. Marquez, J. Med. Chem. 2003, 46, 5045-5054.

[33] T.H. Rabbitts, Nature 1994, 372, 143-149.

[34] G.Q. Daley, R.A. Van Etten, D. Baltimore, Science 1990, 247, 824-830.

[35] D. Brown, S. Kogan, E. Lagasse, I. Weissman, M. Alcalay, P.G. Pelicci, S. Atwater, J.M. Bishop, Proc. Natl. Acad. Sci. USA 1997, 94, 2551-2556.

[36] M.U. Kuefer, A.T. Look, K. Pulford, F.G. Behm, P.K. Pattengale, D.Y. Mason, S.W. Morris, Blood 1997, 90, 2901-2910.

[37] R. Capdeville, E. Buchdunger, J. Zimmermann, A. Matter, Nat. Rev. Drug. Discov. 2002, 1, 493-502.

[38] N. Heisterkamp, K. Stam, J. Groffen, A. de Klein, G. Grosveld. Nature 1985, 315, 758-761.

[39] P. Blume-Jensen, T. Hunter, Nature 2001, $411,355-365$.

[40] A. Cavalli, C. Dezi, G. Folkers, L. Scapozza, M. Recanatini, Proteins 2001, $45,478-485$.
[41] A. Cavalli, A.E. Prota, T. Stehle, T.S. Dermody, M. Recanatini, G. Folkers, L. Scapozza, Biophys. J. 2004, 86, 3423-3431.

[42] C.B. Gambacorti-Passerini, F. Rossi, M. Verga, H. Ruchatz, R. Gunby, R. Frapolli, M. Zucchetti, L. Scapozza, S. Bungaro, L. Tornaghi, P. Pioltelli, E. Pogliani, M. D'Incalci, G. Corneo, Blood Cells Mol. Dis. 2002, 28, 361-372.

[43] C.B. Gambacorti-Passerini, R.H. Gunby, R. Piazza, A. Galietta, R. Rostagno, L. Scapozza, Lancet Oncol. 2003, 4, 75-85.

[44] B. Nagar, W.G. Bornmann, P. Pellicena, T. Schindler, D.R. Veach, W.T. Miller, B. Clarkson, J. Kuriyan, Cancer Res. 2002. 62, 4236-4243.

[45] S. Roumiantsev, N.P. Shah, M.E. Gorre, J. Nicoll, B.B. Brasher, C.L. Sawyers, R.A. Van Etten, Proc. Natl. Acad. Sci. USA 2002, 99, 10700-10705.

[46] N. von Bubnoff, F. Schneller, C. Peschel, J. Duyster, Lancet 2002, 359, 487-491.

[47] J. Drews, Drug. Discov. Today 2003, 8, 411-420.

[48] E. Davidov, J. Holland, E. Marple, S. Naylor, Drug. Discov. Today 2003, 8, 175-183.

[49] P.J. Hunter, T.K. Borg, Nat. Rev. Mol. Cell Biol. 2003, 4, 237-243. 